\title{
Effects of norepinephrine on tissue perfusion in a sheep model of intra-abdominal hypertension
}

\author{
Gonzalo Ferrara ${ }^{1,2 \dagger}$, Vanina S Kanoore Edul ${ }^{1,2 \dagger}$, Juan F Caminos Eguillor ${ }^{2}$, Enrique Martins ${ }^{2}$, Carlos Canullán², \\ Héctor S Canales ${ }^{2}$, Can Ince ${ }^{1}$, Elisa Estenssoro ${ }^{2}$ and Arnaldo Dubin ${ }^{1 *}$
}

\begin{tabular}{l}
\hline * Correspondence: \\
arnaldodubin@gmail.com \\
${ }^{+}$Equal contributors \\
${ }^{1}$ Academic Medical Center, \\
Department of Translational \\
Physiology, University of \\
Amsterdam, Meibergdreef 9, 1105 \\
Amsterdam, AZ, The Netherlands \\
Full list of author information is \\
available at the end of the article
\end{tabular}

* Correspondence:

${ }^{1}$ Academic Medical Center,

Department of Translational

available at the end of the article

\begin{abstract}
Background: The aim of the study was to describe the effects of intra-abdominal hypertension (IAH) on regional and microcirculatory intestinal blood flow, renal blood flow, and urine output, as well as their response to increases in blood pressure induced by norepinephrine.

Methods: This was a pilot, controlled study, performed in an animal research laboratory. Twenty-four anesthetized and mechanically ventilated sheep were studied. We measured systemic hemodynamics, superior mesenteric and renal blood flow, villi microcirculation, intramucosal-arterial $\mathrm{PCO}_{2}$, urine output, and intra-abdominal pressure. IAH (20 mm Hg) was generated by intraperitoneal instillation of warmed saline. After $1 \mathrm{~h}$ of IAH, sheep were randomized to IAH control $(n=8)$ or IAH norepinephrine $(n=8)$ groups, for $1 \mathrm{~h}$. In this last group, mean arterial pressure was increased about $20 \mathrm{~mm} \mathrm{Hg}$ with norepinephrine. A sham group $(n=8)$ was also studied. Fluids were administered to prevent decreases in cardiac output. Differences between groups were analyzed with two-way repeated measures of analysis of variance (ANOVA).
\end{abstract}

Results: After $2 \mathrm{~h}$ of IAH, abdominal perfusion pressure decreased in IAH control group compared to IAH norepinephrine and sham groups $(49 \pm 11,73 \pm 11$, and $86 \pm 15 \mathrm{~mm}$ $\mathrm{Hg}, \mathrm{P}<0.0001)$. There were no differences in superior mesenteric artery blood flow, intramucosal-arterial $\mathrm{PCO}_{2}$, and villi microcirculation among groups. Renal blood flow $\left(49 \pm 30,32 \pm 24\right.$, and $\left.102 \pm 45 \mathrm{~mL} \cdot \mathrm{min}^{-1} . \mathrm{kg}^{-1}, P<0.0001\right)$ and urinary output $(0.3 \pm 0.1$, $0.2 \pm 0.2$, and $1.0 \pm 0.6 \mathrm{~mL} . \mathrm{h}^{-1} . \mathrm{kg}^{-1}, P<0.0001$ ) were decreased in IAH control and IAH norepinephrine groups, compared to the sham group.

Conclusions: In this experimental model of IAH, the gut and the kidney had contrasting responses: While intestinal blood flow and villi microcirculation remained unchanged, renal perfusion and urine output were severely compromised.

Keywords: Intra-abdominal hypertension; Perfusion pressure; Microcirculation; Renal blood flow; Urinary output

\section{Background}

The occurrence of elevated intra-abdominal pressure (IAP) has been increasingly recognized in critically ill patients as a complication of several abdominal and extra-abdominal conditions and also as an independent predictor of mortality [1]. Sustained or repeated values of IAP $\geq 12 \mathrm{~mm} \mathrm{Hg}$ define intra-abdominal hypertension (IAH). IAH may affect organ function and lead to the abdominal compartment

\section{Springer}

(c) 2015 Ferrara et al.; licensee Springer. This is an Open Access article distributed under the terms of the Creative Commons Attribution License (http://creativecommons.org/licenses/by/4.0), which permits unrestricted use, distribution, and reproduction in any medium, provided the original work is properly credited. 
syndrome, which is characterized by a sustained IAP $>20 \mathrm{~mm} \mathrm{Hg}$ plus the development of new organ dysfunctions/failures [2].

The involvement of intra-abdominal organs during IAH is heterogeneous. Clinical and experimental studies showed that the kidney is particularly susceptible, even to small increases in IAP [3], evidenced by decreased glomerular filtration and oliguria. In contrast, the gut compromise in patients with IAH seems to be variable: reports go from overt ischemia with bowel infarction [4], to subtle hypoperfusion generating mucosal barrier dysfunction [5] or intramucosal acidosis [6]. Experimental research also showed dissimilar gut alterations. Some studies found severe reductions in gut perfusion induced by an IAP of $15 \mathrm{~mm} \mathrm{Hg}$ maintained for $2 \mathrm{~h}$ [7], while others showed preservation of intestinal blood flow after $3 \mathrm{~h}$ of $20 \mathrm{~mm} \mathrm{Hg}$ [8]. These contradictory findings might be related to different models of IAH but also to the particular behavior of cardiac output in each animal model. Therefore, the decrease in regional and tissue intestinal blood flow might not be completely dissociated from the alterations in systemic hemodynamics.

The abdominal perfusion pressure (APP) is the difference between mean arterial pressure (MAP) and IAP. The APP is a surrogate of the driving pressure for the perfusion of intra-abdominal organs; and its decrease might thus be the major pathophysiologic mechanism underlying regional hypoperfusion and organ failures. The APP was suggested as a more accurate predictor of visceral perfusion and a better goal of resuscitation than isolated values of IAP or MAP [9]; yet, there is no clinical evidence supporting an APP above $60 \mathrm{~mm} \mathrm{Hg}$ as a therapeutic goal. Accordingly, the World Society for Abdominal Compartment Syndrome makes no recommendation regarding the use of APP in the resuscitation of critically ill patients with IAH [10].

Few experimental studies have evaluated the benefits of increasing MAP on tissue perfusion. Hence, our goal was to describe the effects of IAH on regional and microvascular intestinal perfusion, and on renal blood flow and urinary output, in an adequately resuscitated sheep model. Another aim was to assess the effect of an increase in APP, mediated by norepinephrine.

Our hypothesis was that the IAH produces a heterogeneous compromise in the circulation of intra-abdominal organs and that norepinephrine restores such disorders.

\section{Methods}

This study was approved by the local Animal Research Committee [0800-009634/11-000]. Care of animals was in accordance with National Institutes of Health (United States).

\section{Surgical preparation}

Twenty-four sheep (mean weight, $21 \mathrm{~kg}\left(\mathrm{SD}, 4 \mathrm{~kg}\right.$ )) were anesthetized with $30 \mathrm{mg} \cdot \mathrm{kg}^{-1}$ of sodium pentobarbital, intubated, and mechanically ventilated with a Servo Ventilator 900C (Siemens-Elema AB, Solna, Sweden) with a tidal volume of $15 \mathrm{~mL} . \mathrm{kg}^{-1}$, an $\mathrm{FiO}_{2}$ of 0.21 , and a positive end-expiratory pressure of $6 \mathrm{~cm} \mathrm{H}_{2} \mathrm{O}$. The initial respiratory rate was set to keep the arterial $\mathrm{PCO}_{2}$ between 35 and $40 \mathrm{~mm} \mathrm{Hg}$. This respiratory setting was maintained during the rest of the experiment. Neuromuscular blockade was performed with pancuronium bromide $\left(0.06 \mathrm{mg} \cdot \mathrm{kg}^{-1}\right)$. Additional pentobarbital boluses $\left(1 \mathrm{mg} \cdot \mathrm{kg}^{-1}\right)$ were administered hourly and when clinical signs of inadequate depth of 
anesthesia were evident. Analgesia was provided by fentanyl as a bolus of $2 \mu \mathrm{g} . \mathrm{kg}^{-1}$, followed by $1 \mu \mathrm{g} \cdot \mathrm{h}^{-1} \cdot \mathrm{kg}^{-1}$. These drugs were intravenously administered.

A 7.5 French Swan-Ganz Standard Thermodilution Pulmonary Artery Catheter (Edwards Life Sciences, Irvine, CA, USA) was inserted through an introducer in the right external jugular vein; its side port was used to administer fluids and drugs. A catheter was placed in the descending aorta via the left femoral artery to measure blood pressure and obtain blood samples.

A midline laparotomy was performed, followed by a gastrostomy to drain gastric contents, and a splenectomy to avoid spleen contraction.

Perivascular ultrasonic flow probes were placed around the superior mesenteric artery and the left renal artery, to measure intestinal and renal arterial blood flows.

A catheter was situated in the superior mesenteric vein through a small vein proximal to the gut to draw blood samples. A tonometer was inserted through a small ileotomy to measure intramucosal $\mathrm{PCO}_{2}$.

IAP was measured through a saline-filled catheter positioned in the abdomen, and a tube was left in the left flank for intraperitoneal infusion of saline solution. An ileostomy was constructed on the right flank to allow the mucosa examination. Urinary output was monitored through a catheter inserted into the bladder. Finally, after complete hemostasis, the abdominal wall incision was hermetically closed.

\section{Measurements and derived calculations}

Arterial, systemic, pulmonary, and central venous pressures and IAP were measured at end-expiration with zero set at the midaxillary line (Statham P23 AA, Statham, Hato Rey, Puerto Rico). Cardiac output was measured by thermodilution with $5 \mathrm{~mL}$ of $0^{\circ} \mathrm{C}$ saline solution (HP OmniCare Model 24 A 10, Hewlett Packard, Andover, Mass, USA). The mean value from three measurements taken randomly during the respiratory cycle was subsequently expressed per kilogram of body weight. Superior mesenteric and left renal blood flows were measured by an ultrasonic flowmeter (One Channel Perivascular Flowmeter, Transonics Systems Inc., Ithaca, NY, USA) and normalized to the organ weights.

Urinary output was monitored hourly and indexed to body weight. APP was calculated as MAP - IAP and renal filtration gradient (RFG) as MAP - 2 X IAP [11].

Arterial, mixed venous, and mesenteric venous $\mathrm{PO}_{2}, \mathrm{PCO}_{2}$, and $\mathrm{pH}$ were measured with an ABL5 blood gas analyzer (Radiometer, Copenhagen, Denmark), and hemoglobin and oxygen saturation with an OSM3 cooximeter calibrated for sheep blood (Radiometer). Systemic and intestinal oxygen transports and consumptions $\left(\mathrm{DO}_{2}\right.$ and $\left.\mathrm{VO}_{2}\right)$ were calculated by standard equations and are expressed as indices of body and intestinal weight.

Intramucosal $\mathrm{PCO}_{2}$ was measured with a tonometer (Tonometrics Catheter, Datex-Ohmeda, Helsinki, Finland) through the use of an automated air tonometry system (Tonocap, Datex-Ohmeda, Helsinki, Finland). Its value was used to calculate intramucosal-arterial $\mathrm{PCO}_{2}\left(\triangle \mathrm{PCO}_{2}\right)$.

Arterial lactate, $\left[\mathrm{Na}^{+}\right],\left[\mathrm{K}^{+}\right]$, and $\left[\mathrm{Cl}^{-}\right]$were measured with a point-of-care analyzer (Stat Profile Critical Care Xpress, Nova Biomedical, Waltham, MA, USA). Anion gap was calculated as $\left(\left[\mathrm{Na}^{+}\right]+\left[\mathrm{K}^{+}\right]\right)-\left(\left[\mathrm{Cl}^{-}\right]+\left[\mathrm{HCO}_{3}^{-}\right]\right)$. 


\section{Microcirculatory measurements and analysis}

We evaluated the microcirculatory network in the sublingual and intestinal ileal mucosae with a MicroScan sidestream dark field (SDF) imaging device (MicroVision Medical, Amsterdam, Netherlands) [12]. For the assessment of villi, the device was gently introduced into the abdomen through the ileostomy. Careful precautions and specific steps were taken both to obtain images of adequate quality and to ensure good reproducibility. Experienced researchers performed the video acquisitions and image analyses. Steady images of at least 20 s were obtained to avoid pressure artifacts, by means of a portable computer and an ADVC110 analog-to-digital video converser (Canopus Co, San Jose, CA, USA). Clips were stored as AVI files on the hard disk to allow computerized frame-by-frame image analysis. SDF images were acquired from three different regions in the site of interest, after verifying that focus and contrast adjustment were adequate; poor-quality images were discarded. The whole sequence was used to characterize the microvascular blood flow semi-quantitatively, especially regarding the presence of stopped or intermittent flow.

The video clips were analyzed blindly and randomly. First, we used a modification of a semi-quantitative score, which distinguishes no flow (0), intermittent flow (1), sluggish flow (2), and continuous flow (3). A value was assigned to each individual vessel. The overall score, called the microvascular flow index (MFI), is the mean of the individual vessel values. For each animal, values obtained from three fields were averaged [13]. Second, we used Automated Vascular Analysis (AVA) 3.0, an image analysis software package (Academic Medical Center, University of Amsterdam, Amsterdam, Netherlands) developed for SDF video images, to determine vascular density [14]. Finally, we estimated the percentage of perfused vessels and the total and perfused vascular densities. The former was calculated from the number of vessels with flows of 2 and 3 after division by the total number of vessels and multiplication by 100 . The latter was calculated from the total density, after multiplication by the fraction of perfused vessels. We also determined the heterogeneity of perfusion as the heterogeneity flow index, as the difference between the highest and lowest MFI, divided by the mean MFI [15].

In the sheep, most of sublingual vascular density (97\% (SD, 1\%) of total vessel length, and all villi vessels, consist of small vessels (diameter below $20 \mu \mathrm{m}$ )) [16], so the analysis was focused on these type of vessels.

\section{Experimental procedure}

Basal measurements were taken after a stabilization period of no less than $30 \mathrm{~min}$. Then, warmed saline solution $\left(363 \pm 47 \mathrm{~mL} \cdot \mathrm{kg}^{-1}\right.$ of body weight) was infused to reach an IAP of $20 \mathrm{~mm} \mathrm{Hg}$. IAP was continuously monitored and maintained constant. After $1 \mathrm{~h}$ of IAH, sheep were randomized to IAH control $(n=8)$ or IAH norepinephrine $(n=8)$ groups. In both groups, IAP was maintained for 1 additional hour at $20 \mathrm{~mm} \mathrm{Hg}$; but in the second one, MAP was increased about $20 \mathrm{~mm} \mathrm{Hg}$ by means of norepinephrine to reach $\mathrm{APP}>60 \mathrm{~mm} \mathrm{Hg}$. We also included a sham group $(n=8)$ in which all surgical procedures were performed without infusing intraperitoneal saline solution. An infusion of hydroxyethyl starch 6\% 130/0.4 in $0.9 \% \mathrm{NaCl}$ (Voluven, Fresenius Kabi, Bad Homburg, Germany) was administered throughout the study to maintain the cardiac output constant and to avoid MAPs <60 mm Hg. Measurements were repeated at 60 and $120 \mathrm{~min}$. 
At the end of the experiment, animals were euthanized with an additional dose of pentobarbital and a potassium chloride bolus. A catheter was inserted in the superior mesenteric artery for the instillation of India ink. The dyed intestinal segments were dissected, washed, and weighed to calculate the gut indices. The left kidney was also weighed.

\section{Statistical analysis}

Data were assessed for normality using the Shapiro-Wilk test and expressed as mean \pm SD. Two-way repeated measures analysis of variance (ANOVA) was used for comparison between the three groups. Pairwise comparisons between groups were performed with unpaired $t$-test with Bonferroni correction after a significant time $\mathrm{X}$ group interaction. The relationship between regional blood flow and abdominal perfusion pressure was evaluated with linear regression analysis. A $P$ value $<0.05$ was considered to be significant.

\section{Results}

\section{Systemic effects}

There were no differences in MAP at baseline and at $60 \mathrm{~min}$ among groups; but at $120 \mathrm{~min}$, MAP was lower in the IAH control group compared to the others. APP decreased similarly in IAH control and IAH norepinephrine groups at $60 \mathrm{~min}$. At $120 \mathrm{~min}$, APP in IAH norepinephrine group increased to higher values than in IAH control group, but not different from the sham group. In IAH control and IAH norepinephrine groups, pulmonary and central venous pressures were higher than in the sham group. Cardiac index was similar throughout the experiment in the three groups (Table 1 and Figure 1). The dose of norepinephrine required to reach the target MAP was $0.23 \pm 0.10 \mu \mathrm{g} \cdot \mathrm{min}^{-1} \cdot \mathrm{kg}^{-1}$.

In IAH control and IAH norepinephrine groups, there were comparable reductions of arterial $\mathrm{pH}$ and base excess, partially explained by the increase in the anion gap and in lactate concentration (Table 1). These groups required a larger volume of fluid administration to maintain cardiac output compared to the sham group $(1,001 \pm 246$, $938 \pm 170$, and $376 \pm 105 \mathrm{~mL}$, respectively, $P<0.0001$ ).

\section{Effects on sublingual microcirculation}

None of the sublingual microcirculatory variables changed over time (Additional file 1).

\section{Intestinal effects}

Superior mesenteric artery blood flow (Figure 1 and Table 2), $\Delta \mathrm{PCO}_{2}$ (Table 2), and each villi microvascular variable remained unchanged in the three groups (Additional file 2). We found no relationship between superior mesenteric artery blood flow and APP (Figure 2).

\section{Renal effects}

At 60 and 120 min of IAH, renal blood flow and urinary output were lower in IAH control and IAH norepinephrine groups, compared to the sham group (Figure 1 and Table 2). At $60 \mathrm{~min}$, RFG decreased in IAH control and IAH norepinephrine groups, compared to the sham group. At 120 min, RFG increased in IAH norepinephrine group 
Table 1 Systemic hemodynamics, oxygen transport, and acid-base variables

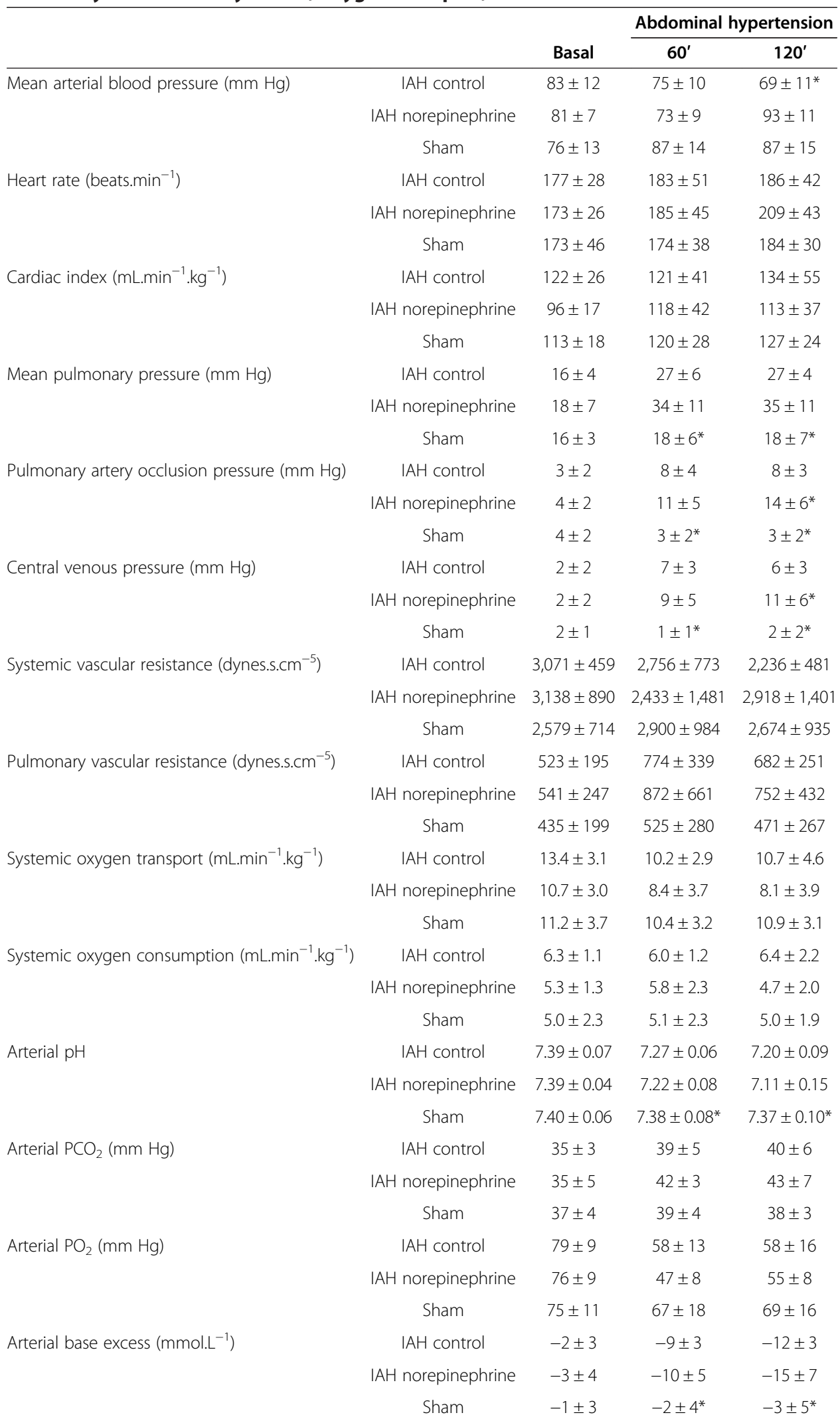


Table 1 Systemic hemodynamics, oxygen transport, and acid-base variables (Continued)

\begin{tabular}{lcccc}
\hline Arterial anion gap $\left(\mathrm{mmol.L}^{-1}\right)$ & IAH control & $12 \pm 3$ & $15 \pm 5$ & $17 \pm 6$ \\
& IAH norepinephrine & $11 \pm 2$ & $14 \pm 4$ & $16 \pm 5$ \\
Arterial lactate $\left(\mathrm{mmol.L}^{-1}\right)$ & Sham & $9 \pm 3$ & $9 \pm 3^{*}$ & $9 \pm 5^{*}$ \\
& IAH control & $1.9 \pm 0.7 \pm$ & $4.0 \pm 2.5$ & $6.9 \pm 2.8$ \\
& IAH norepinephrine & $2.2 \pm 0.5$ & $5.0 \pm 2.9$ & $6.9 \pm 1.8$ \\
& Sham & $1.9 \pm 0.4$ & $1.3 \pm 0.6^{*}$ & $2.6 \pm 0.6^{*}$ \\
\hline
\end{tabular}

${ }^{*} P<0.05$ vs. the other groups.

but remained lower than in the sham group. There were significant correlations between renal artery blood flow and APP (Figure 3) and between renal artery blood flow and urinary output $\left(R^{2}=0.27, P<0.0001\right)$. RFG was correlated with renal blood flow $\left(R^{2}=0.39, P<0.0001\right)$ and urinary output $\left(R^{2}=0.31, P<0.0001\right)$.

\section{Discussion}

The main finding of this study was the contrasting effect of IAH on renal and gut physiology. Renal blood flow and urinary output experienced a sharp decrease while intestinal flow remained unaffected, even after the increase in MAP and APP produced by the infusion of norepinephrine.

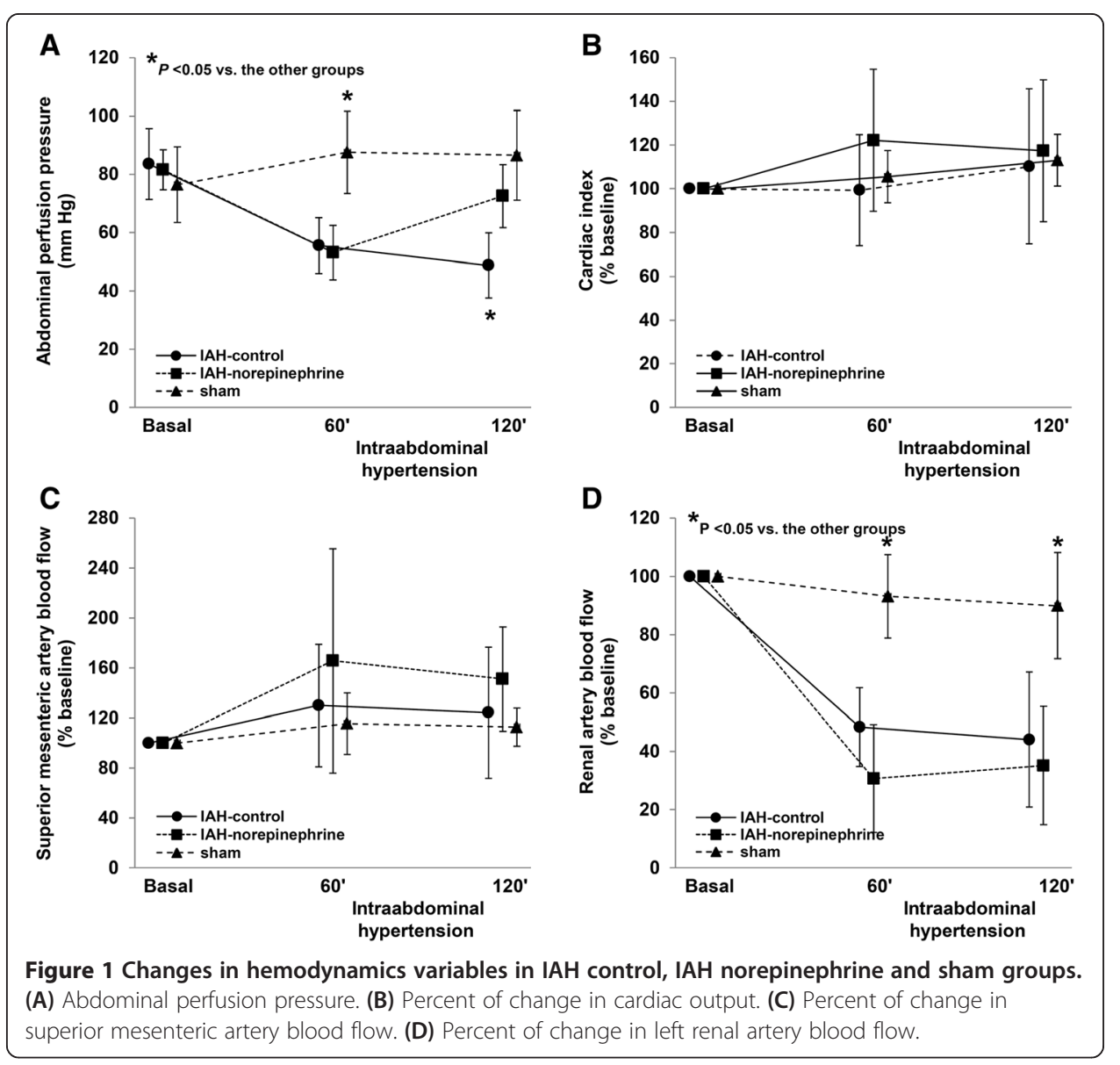


Table 2 Intestinal and renal hemodynamics, oxygen transport, and perfusion variables

\begin{tabular}{|c|c|c|c|c|}
\hline & & \multirow[b]{2}{*}{ Basal } & \multicolumn{2}{|c|}{$\begin{array}{l}\text { Abdominal } \\
\text { hypertension }\end{array}$} \\
\hline & & & $60^{\prime}$ & $120^{\prime}$ \\
\hline \multirow{3}{*}{$\begin{array}{l}\text { Superior mesenteric artery blood flow } \\
\left(\mathrm{mL} \cdot \mathrm{min}^{-1} \cdot \mathrm{kg}^{-1}\right)\end{array}$} & IAH control & $392 \pm 154$ & $524 \pm 302$ & $522 \pm 362$ \\
\hline & IAH norepinephrine & $445 \pm 318$ & $633 \pm 383$ & $634 \pm 401$ \\
\hline & Sham & $405 \pm 115$ & $449 \pm 88$ & $448 \pm 108$ \\
\hline \multirow{3}{*}{$\begin{array}{l}\text { Intestinal oxygen transport } \\
\left(\mathrm{mL} \cdot \mathrm{min}^{-1} \cdot \mathrm{kg}^{-1}\right)\end{array}$} & IAH control & $45.2 \pm 16.5$ & $44.9 \pm 24.6$ & $43.5 \pm 30.9$ \\
\hline & IAH norepinephrine & $49.4 \pm 37.4$ & $44.6 \pm 32.7$ & $45.3 \pm 33.8$ \\
\hline & Sham & $38.6 \pm 9.6$ & $39.2 \pm 11.4$ & $37.8 \pm 10.7$ \\
\hline \multirow{3}{*}{$\begin{array}{l}\text { Intestinal oxygen consumption } \\
\left(\mathrm{mL} \cdot \mathrm{min}^{-1} \cdot \mathrm{kg}^{-1}\right)\end{array}$} & IAH control & $16.9 \pm 5.1$ & $20.7 \pm 10.8$ & $15.8 \pm 11.0$ \\
\hline & IAH norepinephrine & $17.9 \pm 10.7$ & $23.5 \pm 13.4$ & $23.7 \pm 12.5$ \\
\hline & Sham & $14.8 \pm 5.9$ & $15.9 \pm 7.0$ & $15.8 \pm 6.3$ \\
\hline \multirow[t]{3}{*}{ Intramucosal-arterial $\mathrm{PCO}_{2}(\mathrm{~mm} \mathrm{Hg})$} & IAH control & $7 \pm 6$ & $9 \pm 6$ & $8 \pm 5$ \\
\hline & IAH norepinephrine & $11 \pm 7$ & $12 \pm 5$ & $12 \pm 8$ \\
\hline & Sham & $4 \pm 4$ & $4 \pm 6$ & $3 \pm 5$ \\
\hline \multirow[t]{3}{*}{ Renal filtration gradient $(\mathrm{mm} \mathrm{Hg})$} & IAH control & $83 \pm 12$ & $35 \pm 5$ & $29 \pm 11$ \\
\hline & IAH norepinephrine & $81 \pm 7$ & $33 \pm 9$ & $53 \pm 11^{*}$ \\
\hline & Sham & $76 \pm 13$ & $87 \pm 14^{*}$ & $87 \pm 15^{*}$ \\
\hline \multirow[t]{3}{*}{ Renal blood flow (mL.min ${ }^{-1} . \mathrm{kg}^{-1}$ ) } & IAH control & $1,906 \pm 517$ & $943 \pm 416$ & $869 \pm 545$ \\
\hline & IAH norepinephrine & $1,905 \pm 729$ & $552 \pm 359$ & $620 \pm 317$ \\
\hline & Sham & $1,890 \pm 639$ & $1,729 \pm 510^{*}$ & $1,678 \pm 569^{*}$ \\
\hline \multirow[t]{3}{*}{ Renal oxygen transport $\left(\mathrm{mL} \cdot \mathrm{min}^{-1} \cdot \mathrm{kg}^{-1}\right)$} & IAH control & $222 \pm 64$ & $81 \pm 34$ & $75 \pm 43$ \\
\hline & IAH norepinephrine & $214 \pm 01$ & $38 \pm 28$ & $45 \pm 29$ \\
\hline & Sham & $183 \pm 58$ & $147 \pm 37^{*}$ & $144 \pm 54^{*}$ \\
\hline \multirow[t]{3}{*}{ Urinary output $\left(\mathrm{mL} . \mathrm{h}^{-1} \cdot \mathrm{kg}^{-1}\right)$} & IAH control & $1.2 \pm 0.3$ & $0.4 \pm 0.1$ & $0.3 \pm 0.1$ \\
\hline & IAH norepinephrine & $1.1 \pm 0.5$ & $0.4 \pm 0.3$ & $0.2 \pm 0.1$ \\
\hline & Sham & $1.3 \pm 0.6$ & $0.9 \pm 0.5^{*}$ & $1.0 \pm 0.6^{*}$ \\
\hline
\end{tabular}

${ }^{*} P<0.05$ vs. the other groups.

In many experimental studies about IAH, it is difficult to ascertain whether hypoperfusion of intra-abdominal organs is a direct consequence of increased IAP, or just the result of low cardiac output, a well-known deleterious effect of IAH $[17,18]$. IAH may decrease cardiac output by different mechanisms, but the main cause is the reduction in cardiac filling, secondary to increased intrathoracic pressure and decreased venous return from the abdomen and lower limbs [19]. In this model, cardiac output was kept constant by the infusion of fluids. In this way, we ruled out low cardiac output as the cause of intra-abdominal hypoperfusion. Although our study was not aimed at assessing the mechanisms of cardiac output reduction mediated by IAH, our sheep model showed that the increase in preload was able to preserve cardiac output. This finding highlights the relevance of avoiding hypovolemia in IAH.

Experimental research has shown controversial results about the gut involvement in IAH. Some studies describe reductions in mesenteric blood flow and mucosal microcirculation. Severe alterations in the villi microcirculation were reported with $15 \mathrm{~mm} \mathrm{Hg}$ of IAP [20]. Also, rabbits exposed to nitrogen pneumoperitoneum developed reduced mucosal blood flow and increased intestinal permeability, which resulted in endotoxin release to the systemic circulation, mitochondrial damage, and necrosis of the gut mucosa [7]. Even 

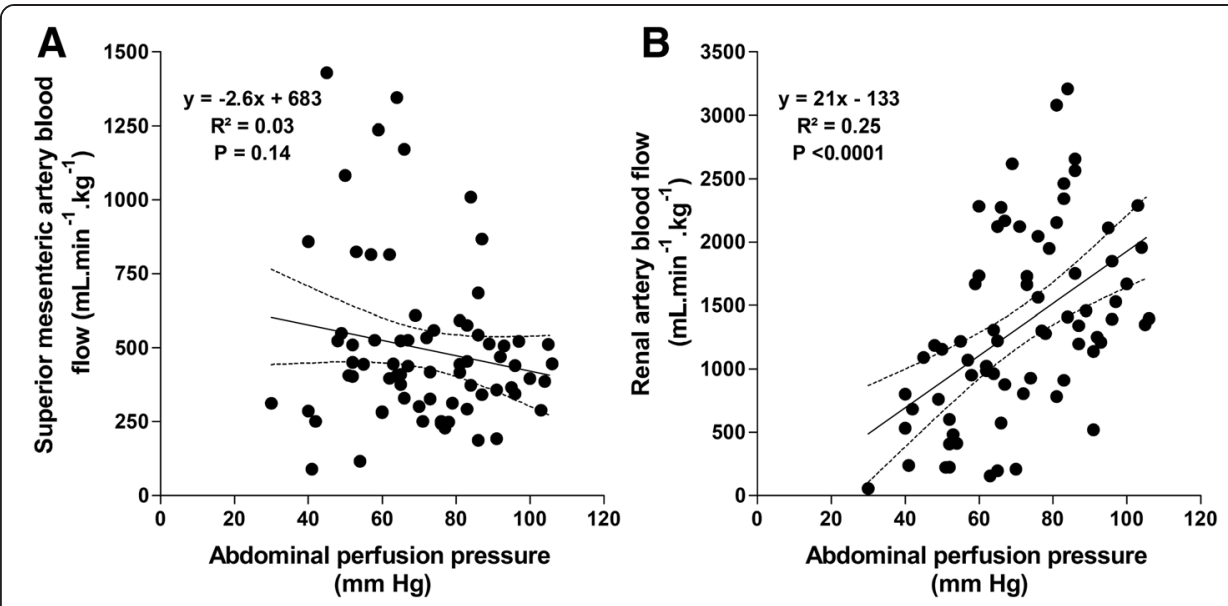

Figure 2 Blood flow/perfusion pressure relationships. (A) Correlation between superior mesenteric artery blood flow and abdominal perfusion pressure. (B) Correlation between left renal artery blood flow and abdominal perfusion pressure.

though these studies warn about the catastrophic consequences of gut ischemia generated by IAH, it is not possible to ensure that the underlying mechanism is tissue hypoperfusion. Since cardiac output was not measured, it cannot be discarded that intestinal ischemia was the result of the compromise of systemic hemodynamics secondary to IAH, instead of increased IAP or reduced APP. Accordingly, in other studies, the changes in intestinal perfusion [21] as all as in other organs were related to the changes in cardiac output, even when MAP and APP were only slightly reduced [18]. An experimental model of intraperitoneal insufflation with $\mathrm{CO}_{2}$ found only subtle reductions in microcirculatory flow in the small bowel mucosa [22], which could be completely explained by decreases in cardiac output.

Accordingly, a main finding of our study, in which cardiac output was maintained stable, was the preservation of intestinal perfusion and oxygenation. We used a comprehensive approach for evaluation that included measurements of regional blood flow, oxygen transport and consumption, tissue $\mathrm{PCO}_{2}$, and videomicroscopy of the villi. After $2 \mathrm{~h}$ of an IAH of $20 \mathrm{~mm} \mathrm{Hg}$ and a mean final APP lower than $50 \mathrm{~mm} \mathrm{Hg}$, all variable values were preserved. In addition, the superior mesenteric artery blood flow was not related to APP. This finding evidences the intestinal ability to autoregulate blood flow at lower driving pressures than other organs, such as the kidney. In line with our results, a previous animal study in which intestinal perfusion pressure was reduced by means of an adjustable clamp showed an ischemic threshold of only $33 \mathrm{~mm} \mathrm{Hg}$ of MAP [23]. Taking everything into account, we might speculate that in IAH, intestinal oxygenation and perfusion are preserved despite the fall in APP, because the intestine has a very low limit of flow autoregulation. The maintenance of cardiac output, however, seems to be required for such preservation.

We found that IAH was associated with severe reductions of renal blood flow and urinary output in face of a preserved cardiac output, implying a decrease in the fraction of cardiac output directed to the kidney. In contrast to intestinal blood flow, renal blood flow was linearly related to APP, suggesting a limited ability for autoregulation. Experimental studies also showed that impairments in renal blood flow and function 
were not corrected just by increasing cardiac output, suggesting that local phenomena might be responsible [11,24]. Conversely, other animal investigations showed a direct dependence of renal blood flow on cardiac output $[18,25]$. These discrepancies might be related to the different models of IAH.

Distinct processes may be responsible for the decrease in glomerular filtration and oliguria in IAH: from the reduction in cardiac output, renal blood flow, and APP to direct parenchymal, cava, renal vein, or ureteral compression and neurohumoral dysfunction [3]. Although this study was not designed to explore these mechanisms, the significant correlation between urinary output and renal artery blood flow, APP, and renal filtration gradient suggests that the decreases in these variables induced by IAH were major determinants of oliguria.

In a previous study in bacteremic and non-bacteremic dogs with IAH, the restoration of APP with norepinephrine resulted in substantial but not complete reversal of the decreases in cardiac output and renal blood flow [24]. In our study, the increase in MAP induced by norepinephrine was associated with significant improvements in APP and RFG compared to IAH control group. In spite of these potentially helpful effects, renal arterial blood flow and urinary output remained as low as in the IAH control group. Although these findings might indicate that the increase in driving pressure was not able to improve perfusion, the positive correlation between APP and renal blood flow suggests that increases $>20 \mathrm{~mm} \mathrm{Hg}$ in MAP and APP might be needed for such purpose. In addition, the RFG was improved but not normalized by norepinephrine. The renal filtration gradient is the fluid mechanical force across the glomerulus and is equal to the difference between glomerular filtration pressure and proximal tubular pressure. The decrease in RFG seems to be crucial to explain the renal impairment during IAH [11]. Therefore, higher increases in blood pressure might have beneficial effects on renal physiology.

There is some concern about the potential detrimental effects of norepinephrine on tissue perfusion because of an excessive vasoconstriction. Indeed, septic patients with preserved sublingual microcirculation showed a detrimental response to increasing doses of norepinephrine [26]. Despite this, we noticed no harmful effects of norepinephrine on a previously well-perfused villi microcirculation.

Notwithstanding the preservation of systemic and intestinal oxygen transport and villi and sublingual microcirculation, an anion gap metabolic acidosis and hyperlactatemia ensued. The ischemia of abdominal wall muscles could play a role in the development of these abnormalities. Studies using microdialysis showed that the increase in tissue lactate-to-pyruvate ratio, a marker of anaerobic metabolism, is more pronounced in the rectus abdominis muscle than in intra-abdominal organs [27], though ischemia could have developed in territories not evaluated, such as stomach, colon, and seromuscular layer of the small intestine. In experimental IAH produced by intraperitoneal insufflation of $\mathrm{CO}_{2}$, small bowel mucosa was better preserved than the rest of microcirculatory gastrointestinal beds [22]. Finally, a decrease in the clearance of lactate secondary to hepatic hypoperfusion might have contributed [28].

This study has some limitations. While our model shared some characteristics with clinical conditions, IAH was not generated from capillary leakage and edema. Unfortunately, a more suitable experimental model has not yet been developed. 
Since only a single step in MAP and APP elevation was studied, we cannot rule out that additional increases in these variables induced by norepinephrine could further improve renal perfusion. Since larger volumes of a chloride-rich solution were infused in IAH groups, the load of chloride could play a role in the decrease of renal blood flow [29]. Also, the administration of a starch solution could have produced deleterious effects on renal function [30]. Other limitations are the short observation period, the lack of histology, and the small sample size. Finally, renal function was assessed only by means of urinary output. Experimental studies on $\mathrm{IAH}$, however, have showed that this variable adequately tracks glomerular filtration $[18,22]$.

\section{Conclusions}

In this experimental model in which systemic hemodynamics was maintained by fluid resuscitation, an IAP of $20 \mathrm{~mm} \mathrm{Hg}$ sustained for $2 \mathrm{~h}$ was associated with large decreases in renal blood flow and urinary output. In contrast, intestinal regional and microcirculatory blood flows were preserved. These findings suggest that the kidney and the gut have different autoregulatory thresholds. In addition, an increase of $20 \mathrm{~mm}$ $\mathrm{Hg}$ in MAP and APP induced by norepinephrine failed to improve kidney perfusion and function. Further studies are needed to define if larger increases in those variables might be useful.

\section{Additional files}

Additional file 1: Changes in sublingual microcirculatory variables in IAH control, IAH norepinephrine, and sham groups.

Additional file 2: Changes in intestinal villi microcirculatory variables in IAH control, IAH norepinephrine and sham groups. (A) Total vascular density. (B) Perfused vascular density. (C) Proportion of perfused vessels. (D) Microvascular flow index. (E) Heterogeneity flow index.

\footnotetext{
Abbreviations

APP: abdominal perfusion pressure; $\mathrm{DO}_{2}$ : oxygen transport; IAH: intra-abdominal hypertension; IAP: intra-abdominal pressure; MAP: mean arterial pressure; MFI: microvascular flow index; RFG: renal filtration gradient; $\mathrm{VO}_{2}$ : oxygen consumption; $\triangle \mathrm{PCO}_{2}$ : intramucosal-arterial $\mathrm{PCO}_{2}$.

Competing interests

Dr Ince has developed SDF imaging and is listed as inventor on related patents commercialized by MicroVision Medical (MVM) under a license from the Academic Medical Center (AMC). He has been a consultant for MVM in the past but has not been involved with this company for more than 5 years now, except that he still holds shares. Braedius Medical, a company owned by a relative of Dr Ince, has developed and designed a hand held microscope called CytoCam-IDF imaging. Dr Ince has no financial relation with Braedius Medical of any sort, i.e., never owned shares, or received consultancy or speaker fees from Braedius Medical. All other authors declare that they have no competing interests.
}

\section{Authors' contributions}

GF, VSKE, JFCE, EM, CC, HSC, and AD carried out the animal experiments and participated in the design of the study. AD performed the statistical analyses and drafted the manuscript. $\mathrm{Cl}$ and $\mathrm{EE}$ participated in the study design and interpretation of the data. All authors discussed the results and participated in the writing of the manuscript. All authors read and approved the final manuscript.

\section{Acknowledgements}

This work was supported by the grant PICT-2010-0495, Agencia Nacional de Promoción Científica y Tecnológica, Argentina.

\section{Author details}

${ }^{1}$ Academic Medical Center, Department of Translational Physiology, University of Amsterdam, Meibergdreef 9, 1105 Amsterdam, AZ, The Netherlands. ${ }^{2}$ Cátedra de Farmacología Aplicada, Facultad de Ciencias Médicas, Universidad Nacional de La Plata, 60 y 120, 1900 La Plata, Argentina. 
Received: 14 October 2014 Accepted: 12 February 2015

Published online: 31 March 2015

\section{References}

1. Malbrain ML, Chiumello D, Cesana BM, Reintam Blaser A, Starkopf J, Sugrue M, Pelosi P, Severgnini P, Hernandez G, Brienza N, Kirkpatrick AW, Schachtrupp A, Kempchen J, Estenssoro E, Vidal MG, De Laet I, De Keulenaer BL, WAKE-Up! Investigators (2014) A systematic review and individual patient data meta-analysis on intra-abdominal hypertension in critically ill patients: the wake-up project. World initiative on Abdominal Hypertension Epidemiology, a Unifying Project (WAKE-Up!). Minerva Anestesiol 80:293-306

2. Malbrain ML, Cheatham ML, Kirkpatrick A, Sugrue M, Parr M, De Waele J, Balogh Z, Leppäniemi A, Olvera C, Ivatury R, D'Amours S, Wendon J, Hillman K, Johansson K, Kolkman K, Wilmer A (2006) Results from the International Conference of Experts on Intra-abdominal Hypertension and Abdominal Compartment Syndrome. I. Definitions. Intensive Care Med 32:1722-1732

3. Mohmand H, Goldfarb S (2011) Renal dysfunction associated with intra-abdominal hypertension and the abdominal compartment syndrome. J Am Soc Nephrol 22:615-621

4. Leduc LJ, Mitchell A (2006) Intestinal ischemia after laparoscopic cholecystectomy. JSLS 10:236-238

5. Al-Bahrani AZ, Darwish A, Hamza N, Benson J, Eddleston JM, Snider RH, Nylén ES, Becker KL, Barclay GR, Ammori BJ (2010) Gut barrier dysfunction in critically ill surgical patients with abdominal compartment syndrome. Pancreas 39:1064-1069

6. Djavani K, Wanhainen A, Valtysson J, Björck M (2009) Colonic ischaemia and intra-abdominal hypertension following open repair of ruptured abdominal aortic aneurysm. Br I Surg 96:621-627

7. Cheng J, Wei Z, Liu X, Li X, Yuan Z, Zheng J, Chen X, Xiao G, Li X (2013) The role of intestinal mucosa injury induced by intra-abdominal hypertension in the development of abdominal compartment syndrome and multiple organ dysfunction syndrome. Crit Care 17:R283

8. Gudmundsson FF, Gislason HG, Dicko A, Horn A, Viste A, Grong K, Svanes K (2001) Effects of prolonged increased intra-abdominal pressure on gastrointestinal blood flow in pigs. Surg Endosc 15:854-856

9. Cheatham ML, White MW, Sagraves SG, Johnson JL, Block EF (2000) Abdominal perfusion pressure: a superior parameter in the assessment of intra-abdominal hypertension. J Trauma 49:621-626

10. Kirkpatrick AW, Roberts DJ, De Waele J, Jaeschke R, Malbrain ML, De Keulenaer B, Duchesne J, Bjorck M, Leppaniemi A, Ejike JC, Sugrue M, Cheatham M, Ivatury R, Ball CG, Reintam Blaser A, Regli A, Balogh ZJ, D'Amours S, Debergh D, Kaplan M, Kimball E, Olvera C, Pediatric Guidelines Sub-Committee for the World Society of the Abdominal Compartment Syndrome (2013) Intra-abdominal hypertension and the abdominal compartment syndrome: updated consensus definitions and clinical practice guidelines from the World Society of the Abdominal Compartment Syndrome. Intensive Care Med 39:1190-1206

11. Wauters J, Claus P, Brosens N, McLaughlin M, Malbrain M, Wilmer A (2009) Pathophysiology of renal hemodynamics and renal cortical microcirculation in a porcine model of elevated intra-abdominal pressure. J Trauma 66:713-719

12. Goedhart PT, Khalilzada M, Bezemer R, Merza J, Ince C (2007) Sidestream dark field (SDF) imaging: a novel stroboscopic LED ring-based imaging modality for clinical assessment of the microcirculation. Opt Express 15:15101-15114

13. Pozo MO, Kanoore Edul VS, Ince C, Dubin A (2012) Comparison of different methods for the calculation of the microvascular flow index. Crit Care Res Pract 2012:102483

14. Dobbe JG, Streekstra GJ, Atasever B, van Zijderveld R, Ince C (2008) Measurement of functional microcirculatory geometry and velocity distributions using automated image analysis. Med Biol Eng Comput 46:659-670

15. Trzeciak S, Dellinger RP, Parrillo JE, Guglielmi M, Bajaj J, Abate NL, Arnold RC, Colilla S, Zanotti S, Hollenberg SM, Microcirculatory Alterations in Resuscitation and Shock Investigators (2007) Early microcirculatory perfusion derangements in patients with severe sepsis and septic shock: relationship to hemodynamics, oxygen transport, and survival. Ann Emerg Med 49:88-98

16. Dubin A, Pozo MO, Ferrara G, Murias G, Martins E, Canullán C, Canales HS, Kanoore Edul VS, Estenssoro E, Ince C (2009) Systemic and microcirculatory responses to progressive hemorrhage. Intensive Care Med 35:556-564

17. Barnes GE, Laine GA, Giam PY, Smith EE, Granger HJ (1985) Cardiovascular responses to elevation of intra-abdominal hydrostatic pressure. Am J Physiol 248(2 Pt 2):R208-R213

18. Lindström P, Källskog O, Wadström J, Persson AE (2003) Blood flow distribution during elevated intraperitoneal pressure in the rat. Acta Physiol Scand 177:149-156

19. Takata M, Wise RA, Robotham JL (1990) Effects of abdominal pressure on venous return: abdominal vascular zone conditions. J Appl Physiol 69:1961-1972

20. Samel ST, Neufang T, Mueller A, Leister I, Becker H, Post S (2002) A new abdominal cavity chamber to study the impact of increased intra-abdominal pressure on microcirculation of gut mucosa by using video microscopy in rats. Crit Care Med 30:1854-1858

21. Agustí M, Elizalde Jl, Adàlia R, Cifuentes A, Fontanals J, Taurà $P$ (2000) Dobutamine restores intestinal mucosal blood flow in a porcine model of intra-abdominal hyperpressure. Crit Care Med 28:467-472

22. Olofsson PH, Berg S, Ahn HC, Brudin LH, Vikström T, Johansson KJ (2009) Gastrointestinal microcirculation and cardiopulmonary function during experimentally increased intra-abdominal pressure. Crit Care Med 37:230-239

23. Lehtipalo S, Biber B, Fröjse R, Arnerlöv C, Johansson G, Winsö O (2003) Effects of dopexamine and positive end-expiratory pressure on intestinal blood flow and oxygenation: the perfusion pressure perspective. Chest 124:688-698

24. Harman PK, Kron IL, McLachlan HD, Freedlender AE, Nolan SP (1982) Elevated intra-abdominal pressure and renal function. Ann Surg 196:594-597

25. Peng ZY, Critchley LA, Joynt GM, Gruber PC, Jenkins CR, Ho AM (2008) Effects of norepinephrine during intra-abdominal hypertension on renal blood flow in bacteremic dogs. Crit Care Med 36:834-841 
26. Dubin A, Pozo MO, Casabella CA, Pálizas F Jr, Murias G, Moseinco MC, Kanoore Edul VS, Pálizas F, Estenssoro E Ince C (2009) Increasing arterial blood pressure with norepinephrine does not improve microcirculatory blood flow: a prospective study. Crit Care 13:R92

27. Meier C, Contaldo C, Schramm R, Holstein JH, Hamacher J, Amon M, Wanner GA, Trentz O, Menger MD (2007) Microdialysis of the rectus abdominis muscle for early detection of impending abdominal compartment syndrome. Intensive Care Med 33:1434-1443

28. Malbrain ML, Viaene D, Kortgen A, De Laet I, Dits H, Van Regenmortel N, Schoonheydt K, Bauer M (2012) Relationship between intra-abdominal pressure and indocyanine green plasma disappearance rate: hepatic perfusion may be impaired in critically ill patients with intra-abdominal hypertension. Ann Intensive Care 2 Suppl 1:S19

29. Wilcox CS (1983) Regulation of renal blood flow by plasma chloride. J Clin Invest 71:726-735

30. Myburgh JA, Finfer S, Bellomo R, Billot L, Cass A, Gattas D, Glass P, Lipman J, Liu B, McArthur C, McGuinness S, Rajbhandari D, Taylor CB, Webb SA, CHEST Investigators; Australian and New Zealand Intensive Care Society Clinical Trials Group (2012) Hydroxyethyl starch or saline for fluid resuscitation in intensive care. N Engl J Med 367:1901-191

\section{Submit your manuscript to a SpringerOpen ${ }^{\circ}$} journal and benefit from:

- Convenient online submission

- Rigorous peer review

- Immediate publication on acceptance

- Open access: articles freely available online

- High visibility within the field

- Retaining the copyright to your article 